\title{
Fetal Death Registration in Multiple Births: Anomalies and Clinical Significance
}

\author{
Peter O. D. Pharoah \\ Department of Public Health, University of Liverpool, Liverpool, United Kingdom
}

\begin{abstract}
$T$ rends in the civil registration of fetal death in multiple gestations that has occurred before, but expelled from the womb after, 24 weeks' gestation are examined using England and Wales 1993-2004 registration obtained from the Office for National Statistics. Count was made of fetal death registrations in which fetus papyraceous, fetal death before 24 weeks' gestation or fetocide before 24 weeks' gestation was recorded. There were 3700 fetal death registrations among 217,595 twin, triplet and higher order multiple births in England and Wales between 1993 and 2004. In 354 (9.6\%) of these fetal deaths, death was recorded as having occurred before 24 weeks' gestation. There has been a threefold increase in such fetal death registrations. It is a legal requirement of parents to register a fetal death. The definition of a fetal death that meets formal registration criteria is that the fetus is expelled from the womb after 24 weeks' gestation. However, if the fetal death occurs before 24 weeks, there is confusion, nationally and internationally, whether or not registration is legally required. Fetal death in a multiple gestation has serious clinical implications for a surviving co-conceptus and failure to inform parents of an early death in a multiple gestation may have important repercussions. Legal definition for the registration of fetal death requires international agreement and application.
\end{abstract}

A fetal death as defined by the World Health Assembly is 'death prior to the complete expulsion or extraction from its mother of a product of conception, irrespective of the duration of the pregnancy' (World Health Organization, 1992, pp. 1235-1236). However, there is international variation in applying this definition. For example, in England and Wales, expulsion after 24 completed weeks of gestation is legally registrable but in most of the United States, expulsion after 20 weeks requires registration. For multiple conceptions there is an additional source of confusion as expulsion with a co-conceptus after 24 weeks' gestation may occur despite early death in utero. Such early fetal deaths usually present as a fetus papyraceous. In multiple conceptions, fetal death of one conceptus has important clinical implications for the co-survivor. The majority of reports note that fetal death of one twin in a monochorionic con- ception is associated with a variety of organ damage in the survivor (Baker \& Doering, 1982; Gonen, 1991; Grafe, 1993; Larroche et al., 1990; Melnick, 1977; Scheller \& Nelson, 1992; Schinzel et al., 1979). Impairment in the survivor may be associated not only with the third trimester but with the second (Anderson et al., 1990; Bordarier \& Robain, 1992; Ishimatsu et al., 1994) and even first trimester fetal death (Baker et al., 1996; Hoyme et al., 1981).

A recent interpretation of the law on registration, where it is known that a fetus had died in utero before 24 weeks but is expelled from the mother after 24 weeks, has led to advice being promulgated by the Royal College of Obstetricians and Gynaecologists (RCOG) that, under the Act, it is not a legal requirement for these cases to be registered as stillbirths (Royal College of Obstetricians and Gynaecologists, 2005).

The adverse clinical prognosis for the co-twin and the confusion over whether fetal death of a twin before, but expulsion after, 24 weeks' gestation, led to this analysis of registered fetal deaths in multiple gestations in England and Wales that is reported here.

\section{Methods}

The Office for National Statistics (ONS) provided annual birth registration data for every multiple gestation in England and Wales from 1993 to 2004. These data record the sex as coded, whether a livebirth or fetal death (stillbirth) and whether the gestation was twin, triplet or higher order.

For all fetal deaths, draft certificates for medical research were provided by ONS. The draft certificate provides a record of the sex as male, female or indeterminate. Those recorded as indeterminate sex were all coded as male until some time in 1998 when coders were instructed to code them alternately male or female. The fetal death certificate also records the cause of death and the gestational age at birth.

Fetus papyraceous (or fetus compressus or mummified fetus) and fetocide occasionally appeared among the causes of death. Although the gestational

\section{Received 14 May, 2006; accepted 17 May, 2006}

Address for correspondence: Peter O. D. Pharoah, Department of Public Health, University of Liverpool, Liverpool L69 3GB, UK. E-mail:p.o.d.pharoah@liv.ac.uk 
age at birth (but not the gestational age at death) is required for the fetal death certificate, nevertheless, the gestational age at fetal death was frequently noted among the causes of death. Similarly, where the cause of death was given as fetocide, many had the gestational age at fetocide recorded. The annual number of fetal deaths in each of three categories, fetus papyraceous, fetal death at less than 24 weeks' gestation and fetocide at less than 24 weeks' gestation was determined. An assumption was made that, for a fetus papyraceous, fetal death occurred at less than 24 weeks' gestation.

\section{Results}

There were 208,828 twin, 8448 triplet and 319 higher-order multiple births in England and Wales between 1993 and 2004 and 3700 fetal deaths were registered. The numbers of registered live-births and fetal deaths by plurality of gestation are shown in Table 1.

As expected, there was an increase in fetal death rate with increasing plurality of birth.

The annual number of fetal death registrations where fetal demise occurred at less than 24 weeks' gestations is shown in Table 2.

ONS policy on disclosure requires that an individual cell in a table must not show a value of less than 5 . For this reason the data in Table 2 have been aggregated in 3-year groups. There has been a striking, about three-fold, increase in each of these registration categories over the 12 -year period. The largest proportional increase has been in fetocides carried out before 24 weeks' gestation. Some of these fetocides were carried out in the first trimester and even embryo reductions have been formally registered as fetal deaths.

If these fetal deaths were to be excluded from the national statistics, over the 12 -year period, the fetal death rate in twins would be reduced from 16.5 to 15.2 , in triplets from 28.3 to 25.3 and in higher order multiples from 74.1 to 35.7 per 1000 total births.

In addition to those fetocides where gestational age at death was recorded as less than 24 weeks, there was a large number of fetocides registered as

\section{Table 1}

Livebirth and Fetal Death Registrations of Multiple Births: England and Wales 1993-2004

\begin{tabular}{lrrrc}
\hline & Live-births & $\begin{array}{c}\text { Fetal } \\
\text { deaths }\end{array}$ & $\begin{array}{c}\text { Total } \\
\text { births }\end{array}$ & $\begin{array}{c}\text { Fetal } \\
\text { death rate } \\
\text { per 1000 } \\
\text { total births }\end{array}$ \\
\hline Twins & 205,389 & 3439 & 208,828 & 16.5 \\
Triplets & 8209 & 239 & 8448 & 28.3 \\
Higher order multiple & 297 & 22 & 319 & 74.1 \\
All multiple births & 213,895 & 3700 & 217,595 & 17.0
\end{tabular}

\section{Table 2}

Registrations of Fetal Deaths of Gestational Age at Death Less Than 24 Weeks

\begin{tabular}{lcccc}
\hline Year & $\begin{array}{c}\text { Fetus } \\
\text { papyraceous } \\
\text { stated among } \\
\text { registered } \\
\text { causes of } \\
\text { stillbirth }\end{array}$ & $\begin{array}{c}\text { Fetus } \\
\text { papyraceous } \\
\text { not mentioned } \\
\text { but age at } \\
\text { fetal death } \\
\text { stated less } \\
\text { than 24 weeks }\end{array}$ & $\begin{array}{c}\text { Fetocide } \\
\text { at less than } \\
\text { 24 weeks } \\
\text { registered } \\
\text { as stillbirth }\end{array}$ & $\begin{array}{c}\text { Total } \\
\text { registered } \\
\text { stillbirths of } \\
\text { gestational } \\
\text { age at death } \\
\text { less than } \\
\text { 24 weeks }\end{array}$ \\
\hline $1993-1995$ & 23 & 16 & 5 & 44 \\
$1996-1998$ & 36 & 17 & 14 & 67 \\
$1999-2001$ & 49 & 25 & 23 & 97 \\
$2002-2004$ & 62 & 51 & 33 & 146 \\
\hline
\end{tabular}

stillbirths for which the gestational age at death was not recorded. An unknown proportion of these possibly were fetocides at less than 24 weeks' gestation. Exclusion of these from registration as stillbirths will further accentuate the artefact of reduction in stillbirth rates in multiple births if they were omitted from national fetal death registrations.

\section{Discussion}

Discussion over whether or not a fetus papyraceous is legally required to be registered has taken place in the correspondence columns of the British Medical Journal (Griffiths, 1997; Heys, 1996; Heys, 1997; Pharoah \& Cooke, 1997). Subsequently, an increase in the number of reported cases in Wessex was noted (Gompels \& Davies, 1999). The increase nationally in the number of cases reported here is probably related to the discussion that has occurred over the important implications this has for surviving co-twins.

The confusion over the legal interpretation of what must be registered is widespread. Clarification was sought from the World Health Organization Collaborating Centre for the Classification of Disease in the United States. The reply stated:

the implications for a fetus papyraceous would be variable. They should be reported in all areas requiring fetal deaths to be reported. They probably would not weigh enough in those areas with requirements based on birthweight but might fit the threshold in areas with requirements based on gestation. The 1992 Revision of the Model State Vital Statistics Act and Regulations recommendation for gestation is to use a calculated value between the date of the last normal menstrual period and date of delivery. This would capture a fetus papyraceous since the key date is the date of delivery rather than presumed date of death. Not all areas specify how gestation is calculated in the reporting requirements, so there may be variability in interpretation in those areas (personal communication).

To what extent there is a similar variation in the interpretation of the World Health Organization definition of a fetal death in other countries is not known. 
Omission of these fetal deaths will have only a marginal effect on stillbirth and perinatal mortal rates. The information is of far more serious relevance to parents because of the high risk of serious morbidity in any surviving co-conceptus. Numerous reports highlight the serious adverse prognosis for a twin whose co-twin died in utero. Abnormality in the surviving twin may be observed in a variety of organs. Most frequently cerebral impairment with microcephaly, multicystic encephalopathy, porencephaly and hydranencephaly, often presenting as cerebral palsy, has been reported. Other organs that are affected may present as a range of congenital anomalies such as the gut atresias including tracheo-oesophageal fistula, cardiac valve atresia or stenosis, coarctation of the aorta, renal agenesis and cutis aplasia. These abnormalities in the surviving fetus, almost invariably, have been reported in monochorionic twin pregnancies (Anderson et al., 1990; Baker \& Doering, 1982; Grafe, 1993; Hoyme et al., 1981; Scheller \& Nelson, 1992; Schinzel et al., 1979). The risk of cerebral palsy in the surviving twin of a co-twin that died in utero is about 1 in 10 (Grether et al., 1993; Pharoah \& Cooke, 1996; Pharoah \& Adi, 2000). It has been hypothesized that the early demise of an embryo or fetus that is unrecognized or unregistered is the cause of many congenital anomalies, including cerebral palsy, in singleton births (Pharoah, 2005).

It is recognized that monochorionicity in a multiple gestation carries a particularly poor prognosis. Therefore, embryo reduction and fetocide need to be considered separately from the spontaneous demise of a conceptus at less than 24 weeks' gestational age. Embryo reduction generally follows assisted reproduction and the conceptuses are dizygotic, dichorionic. The surviving conceptus is not at specifically increased risk (Berkowitz, 1996). Similarly, fetocide in a dichorionic pregnancy does not pose a specific risk but, in a monochorionic pregnancy, death of both fetuses frequently occurs.

Spontaneous fetal demise in a monochorionic multiple gestation, however, has important prognostic implications for the survivor, irrespective of the gestational age of fetal death. It is a legal requirement that parents have to register a stillbirth and concern has been expressed that informing the parents of a fetus papyraceous is distressing and painfully inappropriate (Heys, 1996). Removing the legal requirement to register a fetus papyraceous absolves the obstetrician or midwife from informing the parent. Whether this is appropriate needs to be widely debated. Although the RCOG has been advised that registration of a fetus papyraceous is not a legal obligation under the Births and Deaths Registrations Act, such advice could be challenged in court if the surviving co-twin suffers from cerebral palsy or other serious anomaly.

The new ruling has significant implications for epidemiological research. If many singleton births with congenital anomalies are attributable to fetal loss of one conceptus, national population-based birth registration data will lose its usefulness.

\section{Conclusion}

Fetal death of a conceptus in a multiple gestation, irrespective of the gestational age at death, has potentially serious clinical implications for the surviving co-conceptus(es). Excluding fetal deaths that occur before but are expelled after 24 weeks' gestation from legal registration has important epidemiological research and, possibly, medico-legal consequences. The debate on fetal death registration needs to be pursued, not only in England and Wales but worldwide. Formal definition of fetal death for the International Classification of Diseases needs revision and implementation.

\section{Acknowledgments}

The help of Nirupa Dattani and colleagues at ONS for providing the data files and for answering numerous enquiries about the data is gratefully acknowledged. Formal approval for the release of the data by the Office for National Statistics was obtained.

\section{$\overline{\text { References }}$}

Anderson, R. L., Golbus, M. S., Curry, C. J. R., Callen, P. W., \& Hastrup, W. H. (1990). Central nervous system damage and other anomalies in surviving fetus following second trimester antenatal death of co-twin. Prenatal Diagnosis, 10, 513-518.

Baker, E. M., Khorasgani, M. G., Gardner-Medwin, D., Gholkar, A., \& Griffiths, P. D. (1996). Arthrogryposis multiplex congenita and bilateral parietal polymicrogyria in association with the intrauterine death of a twin. Neuropediatrics, 27, 54-56.

Baker. V. V., \& Doering, M. C. (1982). Fetus papyraceus: An unreported congenital anomaly of the surviving infant. American Journal of Obstetrics and Gynecology, 143, 234-235.

Berkowitz, R. L. (1996). From twin to singleton. British Medical Journal, 313, 373-374.

Bordarier, C., \& Robain, O. (1992). Microgyric and necrotic cortical lesions in twin fetuses: Original cerebral damage consecutive to twinning? Brain and Development, 14, 174-178.

Gonen, R. (1991). The origin of brain lesions in survivors of twin gestations complicated by fetal death. American Journal of Obstetrics and Gynecology, 161, 1897-1898.

Grafe, M. R. (1993). Antenatal cerebral necrosis in monochorionic twins. Pediatric Pathology, 13,15-19.

Grether, J. K., Nelson, K. B., \& Cummins, C. K. (1993). Twinning and cerebral palsy: Experience in four Northern Californian counties, births 1983 through 1985. Pediatrics, 92, 854-858.

Griffiths, M. (1997). Health professionals can exercise discretion. British Medical Journal, 314, 442. 
Gompels, M. J., \& Davies, D. (1999). Fetus papyraceus is being increasingly registered in Wessex. British Medical Journal, 319, 1271.

Heys, R. F. (1996). Selective abortion: Dead fetuses might have to be registered as stillbirths. British Medical Journal, 313, 1004.

Heys, R. F. (1997). Regulations on registration of a fetus papyraceus need to be revised. British Medical Journal, 314, 1352-1353.

Hoyme, E. H., Higginbottom, M. C., \& Jones, K. L. (1981). Vascular etiology of disruptive structural defects in monozygotic twins. Pediatrics, 67, 288-291.

Ishimatsu, J., Hori, D., Miyajima, S., Hamada, T., Yakushiji, M., \& Nishimi, T. (1994). Twin pregnancies complicated by the death of one fetus in the second or third trimester. Journal of Maternal-Fetal Investigation, 4, 141-145.

Larroche, J. C., Droulle, P., Delezoide, A. L., Narcy, F., \& Nessmann, C. (1990). Brain damage in monozygous twins. Biology of the Neonate, 57, 261-278.

Melnick, M. (1977). Brain damage in survivor after death of the monozygotic co-twin. Lancet, 2, 1287.

Pharoah, P. O. D. (2005). Causal hypothesis for some congenital anomalies. Twin Research and Human Genetics, $8,543-550$.
Pharoah, P. O. D., \& Adi, Y. (2000). Consequences of inutero death in a twin pregnancy. Lancet, 355, 1597-1602.

Pharoah, P. O. D., \& Cooke, T. (1996). Cerebral palsy and multiple births. Archives of Disease in Childhood. Fetal and Neonatal Edition, 75, F174-F177.

Pharoah, P. O. D., \& Cooke, R. W. I. (1997). Registering a fetus papyraceus. British Medical Journal, 314, 441-442.

Royal College of Obstetricians and Gynaecologists. (2005, January). Registration of stillbirths and certification for pregnancy loss before 24 weeks gestation. Good Practice No. 4.

Scheller, J. M., \& Nelson, K. B. (1992). Twinning and neurologic morbidity. American Journal of Diseases of Children, 146, 1110-1113.

Schinzel, A. A., Smith, D. W., \& Miller, J. R. (1979). Monozygotic twinning and structural defects. Journal of Pediatrics, 95, 921-930.

World Health Organization. (1992). International statistical classification of diseases and bealth related problems (Vol. 1, 10th Rev.). Geneva: Author. 